\title{
An Exploration Perspective of Beamed Energy Propulsion
}

\author{
John Cole \\ NASA Marshall Space Flight Center \\ Marshall Space Flight Center, AL 35812
}

\begin{abstract}
The Vision for Exploration is currently focused on flying the Space Shuttle safely to complete our Space Station obligations, retiring the Shuttle in 2010, then returning humans to - the Moon and learning how to proceed to Mars and beyond. The NASA budget still includes funds for science and aeronautics but the primary focus is on human exploration. Fiscal constraints have led to pursuing exploration vehicles that use heritage hardware, particularly existing boosters and engines, with the minimum modifications necessary to satisfy mission requirements. So, pursuit of immature technologies is not currently affordable by NASA. Beamed energy is one example of an immature technology, from a human exploration perspective, that may eventually provide significant benefits for human exploration of space, but likely not in the near future. Looking to the more distant future, this paper will examine some of the criteria that must be achieved by beamed energy propulsion to eventually contribute to human exploration of the solar system. The analysis focuses on some of the implications of increasing the payload fraction of a launch vehicle, with a quick look at trans-lunar injection. As one would expect, there is potential for benefit, and there are concerns. The analysis concludes with an assessment of the Technology Readiness Level (TRL) for some beamed energy propulsion components, indicating that TRL 2 is close to being completed.
\end{abstract}

Keywords: Beamed Energy Propulsion, Beamed Power, Launch Vehicles, Exploration Missions, Technology Readiness.

PACS: $07.87 .+\mathrm{v}, 41.75 . \mathrm{Jv}, 84.60 . \mathrm{h}, 84.60 . \mathrm{Bk}, 84.60 . \mathrm{Lw}$

\section{INTRODUCTION}

Human exploration of space requires enormous quantities of material to be delivered to space on a somewhat regular basis. Support of a lunar base with logistics flights every 6 months or so, including both transfer and lander vehicles with lunar base equipment and consumables, will likely require more than 100 metric tons (MT) to low Earth orbit (LEO) for each launch. The current NASA plan is to utilize a heavy lift vehicle, Ares V, to deliver $\approx 120 \mathrm{MT}$ to LEO and a smaller $22 \mathrm{MT}$ payload launch vehicle, Ares I, to deliver human crews in the crew exploration vehicle, Orion, to the Space Station or to rendezvous with the Ares V payloads destined for the Moon. To support a Mars mission will require human rated vehicles similar in size to the Space Station to deliver the crew to Mars and to support the surface excursions. The Space Station was, and is continuing to be, assembled using the Space Shuttle, each flight carrying $\approx 20 \mathrm{MT}$ of equipment. The large number of flights needed for assembly clearly leads to an exploration requirement to deliver much larger segments to reduce 
the number of assembly flights for each expedition. However, the discussions in this paper will concentrate on launch vehicles with a 25 MT payload capability to LEO .

Beamed energy propulsion can only become competitive with current launch vehicle technologies when it can provide compelling benefits to performance and costs. For example, doubling the payload fraction $\left(m_{p l} / m_{0}\right.$, where $m_{p l}$ is the mass of the payload and $m_{0}$ is the gross lift-off weight or GLOW) of a launch vehicle without increasing launch costs would be a compelling benefit. To support exploration missions, the vehicle should deliver at least $25 \mathrm{MT}$ to LEO. Larger vehicles delivering $125 \mathrm{MT}$ to LEO would be desirable but their power requirements would also grow by a factor of 5 .

\section{BASIS OF COMPARISON}

How much power and energy is required for a rocket to reach LEO?

A chemically-powered launch vehicle obtains all of the energy gain from burning the propellants. Once in a circular orbit, the velocity of a vehicle or spacecraft is given by Eq. 1, where $v_{\nu}$ is the vehicle inertial velocity, $\mu_{e}$ is the gravitational parameter for the Earth, $r_{0}$ is the average radius of the Earth, and $h$ is the altitude of the orbit [1]:

$$
v_{v}^{2}=\frac{\mu_{e}}{r_{0}+h}
$$

Thus, a spacecraft in a 200 -km-altitude circular orbit has a velocity of $\approx 7.79 \mathrm{~km} / \mathrm{s}$, and from Eq. 2 that represents a specific kinetic energy $\left(K E_{s p}\right)$ of $\approx 30.3 \mathrm{MJ} / \mathrm{kg}$ :

$$
K E_{s p}=v_{v}^{2} / 2 \text {. }
$$

To achieve a $200-\mathrm{km}$ orbit from an airless Earth, the energy integral, Eq. 3, requires $\approx 7.97 \mathrm{~km} / \mathrm{s}$ of velocity at the surface of the Earth to place the vehicle into an elliptical orbit with an apogee of $200 \mathrm{~km}$, where $a$ is the semi-major axis of the elliptical transfer orbit and $v_{p}$ is the velocity at perigee, assumed to be the Earth surface [1]:

$$
v_{p}^{2}=\mu_{e}\left(\frac{2}{\left(r_{0}+h\right)}-\frac{1}{a}\right) .
$$

The rotation of the Earth at $28.5^{\circ}$ latitude provides $\approx 0.4 \mathrm{~km} / \mathrm{s}$ of this required velocity for a due-East launch. But then there are several velocity losses that must also be overcome by the rocket. Acceleration parallel to local gravity does not contribute to the required orbit velocity, and this acceleration over a finite burn time $\left(t_{\text {burn }}\right)$ will represent a gravity loss $\left(v_{G L}\right)$ that can be approximated by Eq. 4 [2]:

$$
v_{G L}=g * \cos \left(\phi_{a v g}\right) * t_{b u r n},
$$


where $\phi_{a v g}$ is the time average path angle. If we assume a finite burn time of $\approx 600 \mathrm{~s}$ and an average path angle of $\approx 80^{\circ}$, then the expected gravity loss, from Eq. 4 , will be $\approx 1.1 \mathrm{~km} / \mathrm{s}$.

Since the Earth is not airless, there will also be drag losses, typically $\approx 0.5 \mathrm{~km} / \mathrm{s}$, and there will be some steering losses, typically $\approx 0.1 \mathrm{~km} / \mathrm{s}$. So, the total change in ideal velocity required to achieve a $200-\mathrm{km}$-altitude orbit apogee is $\approx 9.2 \mathrm{~km} / \mathrm{s}$. Another $0.06 \mathrm{~km} / \mathrm{s}$ will be required to circularize the orbit at apogee. The exact values for these delta velocity $(\Delta V)$ partitions are, of course, dependent on the specific vehicle and trajectory characteristics, but these values are more or less representative and are summarized in Table 1.

A $\Delta V$ of $9.2-\mathrm{km} / \mathrm{s}$ represents a specific energy of $\approx 42.3 \mathrm{MJ} / \mathrm{kg}$ for the mass that eventually reaches orbit apogee at $200 \mathrm{~km}$. For the rocket, this energy must come entirely from consuming the propellant. The rocket exhaust velocity $\left(v_{e x}\right)$ and the propellant specific energy $\left(E_{s p}\right)$ can be determined from propellant specific impulse $\left(I_{s p}\right)$, using Eqs. 5 and 6:

$$
\begin{gathered}
v_{e x}=g_{0}{ }^{*} I_{s p} \\
E_{s p}=v_{e x}{ }^{2} / 2 .
\end{gathered}
$$

The Space Shuttle main engine, using liquid hydrogen and liquid oxygen propellant as an oxidizer/fuel ratio of 6 , has an approximate $I_{s p}=456 \mathrm{~s}$ [3]. This produces an average exhaust velocity of $\approx 4.47 \mathrm{~km} / \mathrm{s}$ and a propellant specific energy of $\approx 10 \mathrm{MJ} / \mathrm{kg}$, substantially less than the specific energy of the mass delivered to orbit. The burning propellant increases the velocity and kinetic energy of the vehicle and its remaining propellant. To achieve a given $\Delta V$, the required propellant mass fraction $(f)$ is determined from the rocket equation

$$
f_{f}=1-\exp \left(-\Delta V / v_{e x}\right)
$$

and the payload fraction

$$
B=m_{p l} / m_{0}=\left(f_{s}-f_{f}\right) / f_{s},
$$

where $f_{s}$ is the propellant mass fraction of the stage without the payload and is determined by design and manufacturing capability. Table 2 shows some stage propellant mass fractions for a few vehicle stages. Using Eq. 7 with the $\Delta V$ and $I_{s p}$

TABLE 1. Typical ideal velocity components for launch to a $200-\mathrm{km}$-altitude orbit.

\begin{tabular}{l|r|l}
\hline Symbol & \multicolumn{1}{|c}{ Value } & \multicolumn{1}{c}{ Description } \\
\hline$v_{p}$ & $7.97 \mathrm{~km} / \mathrm{s}$ & Perigee velocity at surface of airless Earth \\
$v_{e}$ & $-0.4 \mathrm{~km} / \mathrm{s}$ & Velocity gained from rotation of Earth at $28^{\circ}$ latitude \\
$v_{G L}$ & $1.1 \mathrm{~km} / \mathrm{s}$ & Gravity losses \\
$v_{\text {drag }}$ & $0.5 \mathrm{~km} / \mathrm{s}$ & Drag losses \\
$v_{\text {steer }}$ & $0.1 \mathrm{~km} / \mathrm{s}$ & Steering losses \\
$v_{\text {circ }}$ & $0.06 \mathrm{~km} / \mathrm{s}$ & Velocity required to circularize orbit at apogee \\
$\Delta V$ & $9.26 \mathrm{~km} / \mathrm{s}$ & Ideal $\Delta V$ \\
\hline
\end{tabular}


TABLE 2. Stage propellant mass fraction for historical stages and the evolved expendable launch vehicle [3].

\begin{tabular}{|c|c|c|c|c|c|c|}
\hline Vehicle & Stage & Propellant & $\begin{array}{c}\text { Fuel Mass } \\
(\mathrm{K} \mathrm{kg})\end{array}$ & $\begin{array}{c}\text { Gross Mass } \\
(\mathrm{K} \mathrm{kg})\end{array}$ & $\begin{array}{c}\text { Thrust } \\
\text { (KN) }\end{array}$ & $\begin{array}{c}\text { Stage } \\
\text { Propellant } \\
\text { Mass } \\
\text { Fraction } \\
\left(f_{s}\right)\end{array}$ \\
\hline Saturn V & $\begin{array}{l}\text { S-IC } \\
\text { S-II } \\
\text { S-IVB }\end{array}$ & $\begin{array}{l}\text { LOX/RP-1 } \\
\text { LOX/H } \\
\text { LOX/H }\end{array}$ & $\begin{array}{r}2080 \\
450 \\
108\end{array}$ & $\begin{array}{l}2210 \\
486 \\
119\end{array}$ & $\begin{array}{r}34500 \\
5115 \\
690\end{array}$ & $\begin{array}{l}0.9412 \\
0.9259 \\
0.9076\end{array}$ \\
\hline Titan IV & $\begin{array}{l}\text { Stg } 1 \\
\text { Stg } 2 \\
\text { Centaur }\end{array}$ & $\begin{array}{l}\mathrm{N}_{2} \mathrm{O}_{4} / \mathrm{AZ50} \\
\mathrm{N}_{2} \mathrm{O}_{4} / \mathrm{AZ51} \\
\mathrm{LOX} / \mathrm{H}_{2}\end{array}$ & $\begin{array}{c}155 \\
35.1 \\
20.32\end{array}$ & $\begin{array}{l}163 \\
39.6 \\
23.86\end{array}$ & $\begin{array}{r}2410 \\
462 \\
146\end{array}$ & $\begin{array}{l}0.9509 \\
0.8864 \\
0.8516\end{array}$ \\
\hline Delta IV-H & $\begin{array}{l}\text { Stg } 1 \\
\text { Stg } 2\end{array}$ & $\begin{array}{l}\mathrm{LOX} / \mathrm{H}_{2} \\
\mathrm{LOX} / \mathrm{H}_{2}\end{array}$ & $\begin{array}{r}199.6 \\
27.2\end{array}$ & $\begin{array}{c}226.4 \\
30.71\end{array}$ & $\begin{array}{r}2890 \\
110\end{array}$ & $\begin{array}{l}0.8816 \\
0.8857\end{array}$ \\
\hline Atlas V & $\begin{array}{l}\text { Stg } 1 \\
\text { Centaur III }\end{array}$ & $\begin{array}{l}\mathrm{LOX} / \mathrm{RP}-1 \\
\mathrm{LOX} / \mathrm{H}_{2}\end{array}$ & $\begin{array}{c}284.5 \\
20.83 \\
\end{array}$ & $\begin{array}{c}305.4 \\
22.96 \\
\end{array}$ & $\begin{array}{l}860.2 \\
198.4\end{array}$ & $\begin{array}{l}0.9316 \\
0.9072\end{array}$ \\
\hline
\end{tabular}

values mentioned above, the vehicle propellant mass fraction $\left(f_{f}\right)$ is $\approx 87.4 \%$. If a vehicle can be built with a stage propellant mass fraction $\left(f_{s}\right)$ of $89 \%$, then from Eq. 8 , the payload fraction $(B)$ would be $\approx 1.8 \%$. Attempts to actually design such singlestage-to-orbit (SSTO) vehicles have not been successful, particularly for reusable launch vehicles; the margins are just too small, or even negative. Multistage vehicles have a payload fraction of 3 or 4 , so a new technology vehicle may need to perform significantly better than this. For academic consideration, such an SSTO vehicle that could deliver $25 \mathrm{MT}$ to LEO would have a GLOW (or $\left.m_{0}\right)$ of $\approx 1380 \mathrm{MT}$.

The specific jet power $\left(P_{s p}\right)$ and the total jet power for lift-off $\left(P_{v}\right)$ can be found from Eqs. 9 and 10, given the vehicle initial acceleration $\left(a_{0}\right)$ :

$$
\begin{aligned}
& P_{s p}=a_{0} * v_{e x} / 2 \\
& P_{v}=m_{0} * P_{s p} .
\end{aligned}
$$

For an initial acceleration of 1.4 gees $(13.7 \mathrm{~m} / \mathrm{s})$ the $P_{s p}$ is $\approx 31 \mathrm{KW} / \mathrm{kg}$, and the total power in the jet for the vehicle is more than $42 \mathrm{GW}$. Hydrogen $\left(\mathrm{H}_{2}\right)$ and oxygen $\left(\mathrm{O}_{2}\right)$ propellants deliver the highest $I_{s p}$ of currently available rocket propellants, yet an SSTO vehicle is still too marginal to be practical, and in reality, may not be possible.

The story looks more interesting with improved $I_{s p}$ as shown in Fig. 1. If one could add kinetic energy to the exhaust of this rocket engine to increase the $I_{s p}$ by $100 \mathrm{~s}$ without decreasing $f_{s}$, then the payload fraction would be increased to $\approx 7.8 \%$ and the total jet power at lift-off requirement would be reduced to $\approx 11.8 \mathrm{GW}$.

What does this mean for a beamed-power vehicle? Unless more energetic propellants are found or some other ultra-high-energy storage device is developed, the energy for higher $I_{s p}$ must come from off-board the vehicle. Air-breathing engines and beamed power (or perhaps a combination) are options-possibly the only options. 


\section{PSEUDO-CONCEPT FOR A BEAMED POWER LAUNCH VEHICLE}

The following concept does not really represent any particular beamed energy concept and even may not be applicable to any. However, it has provided some insight into what may be required for possible applications to launch vehicles that could support human exploration missions. For analysis purposes, assume that a nonreusable, 25 MT payload to LEO, SSTO vehicle with $\mathrm{H}_{2}+\mathrm{O}_{2}$ engines has a beamed energy receiver that delivers the power to an engine augmenter that increases the exhaust velocity. Thrust augmentation may be achieved using laser ablation, lasersupported detonations (LSD), magnetohydrodynamics (MHD), or some other technique. Also, assume that a beamed energy transmitter is located at the launch site, and on-board ships if others are needed so that they can be relocated for various mission-specific requirements. Assume that the vehicle launches vertically with 1.4 gees of acceleration and within $600 \mathrm{~s}$ achieves sufficient velocity into a transfer orbit with an apogee of $200 \mathrm{~km}$ in about $180^{\circ}$ of central angle.

The beamed energy receiver and augmenter will likely add some mass to the vehicle and will shift the performance curve. Figure 2 shows the GLOW for three cases where the mass $\left(m_{B E}\right)$ of the beamed energy equipment: (1) is twice the vehicle payload, (2) is equal to the payload, and (3) is equal to zero. Figure 1 indicates that the payload fraction can be increased to $7.8 \%$ if the $I_{s p}$ is increased to $550 \mathrm{~s}$ with no increase in vehicle mass for the $m_{B E}$. However, Fig. 2 shows that if the $m_{B E}$ is twice the payload mass, then the beamed energy equipment must have the capability to increase the $I_{s p}$ to $850 \mathrm{~s}$ to have the same GLOW as the case where $m_{B E}=0$ and $I_{s p}=550 \mathrm{~s}$.

For 1.4 gees of acceleration, Fig. 3 indicates that our propellant can provide $\approx 30$ $\mathrm{KW} / \mathrm{kg}$ from chemistry but $67 \mathrm{KW} / \mathrm{kg}$ is required for a jet to provide $I_{s p}=1000 \mathrm{~s}$; so, beamed energy must provide more than half the power to achieve this example. This, of course, must be multiplied by the chain of conversion efficiencies to arrive at the requirements of the power-beaming device, probably more than an order of magnitude.

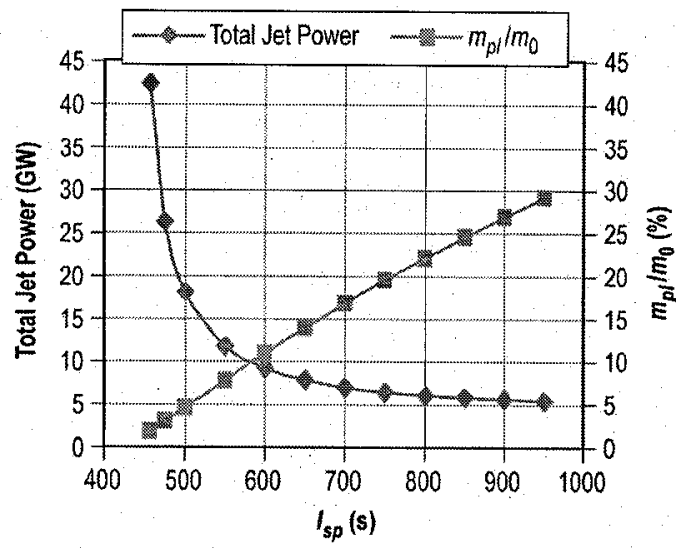

FIGURE 1. Total lift-off jet power and payload ratio for a $25 \mathrm{MT}$ payload $\mathrm{H}_{2}+\mathrm{O}_{2}$ SSTO vehicle.

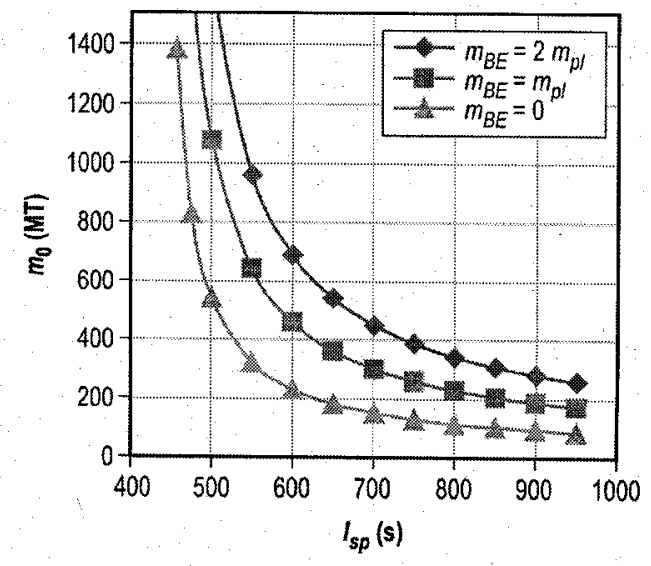

FIGURE 2. Gross lift-off weight for SSTO with $25 \mathrm{MT}$ to LEO. 


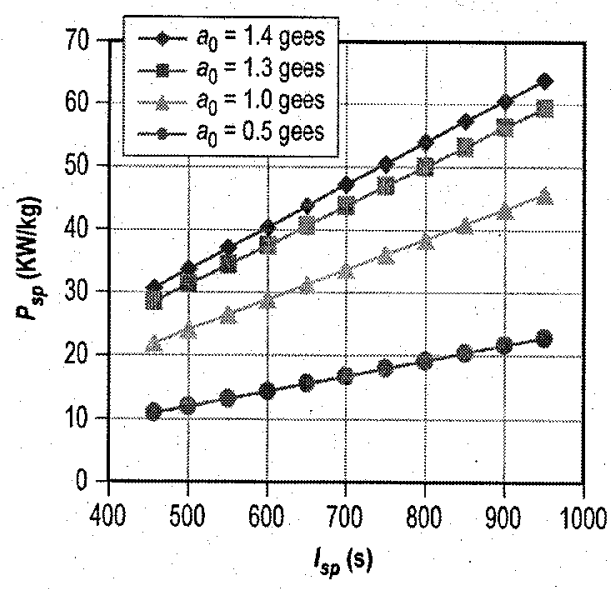

FIGURE 3. Specific jet power versus $I_{s p}$ for given acceleration.

Figure 4 shows the total lift-off jet power needed for this vehicle for the range of $I_{s p}$ and for the three $m_{B E}$ cases described above. Lower $m_{B E}$ significantly reduces lift-off jet power.

Figure 5 shows the variation of the payload fraction with $I_{s p}$ for each of the three $m_{B E}$ cases described above. To achieve a payload fraction of 7.5 with $m_{B E}$; twice the payload mass will require $850 \mathrm{~s}$ of $I_{s p}$, and the total jet power for lift-off will be $\approx 17.5 \mathrm{GW}$. Once again, the transmitted power is increased by the efficiency chain from the jet back to the ground- or ship-based equipment.

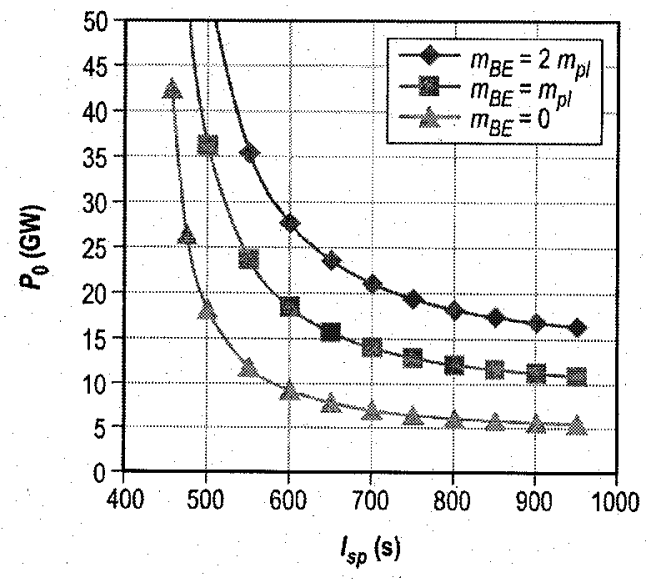

FIGURE 4. Lift-off jet power for SSTO with 25 MT to LEO.

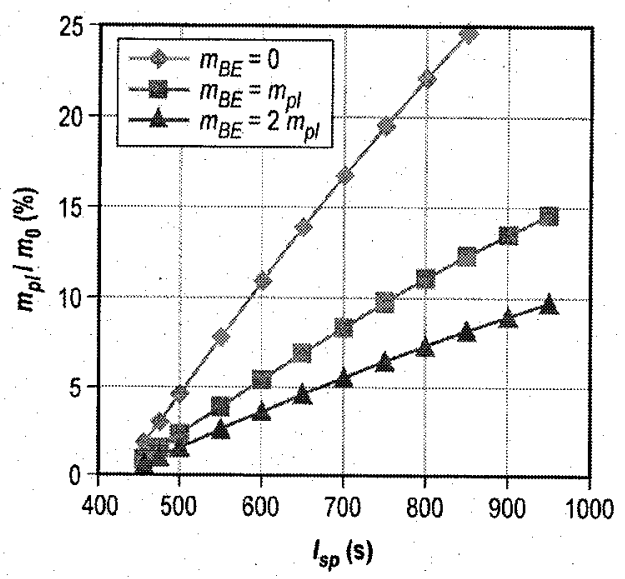

FIGURE 5. Payload fraction for SSTO with 25 MT to LEO. 


\section{AREAS OF CONCERN}

New potential solutions also bring new concerns and there are many that need to be mentioned.

One obvious concern is that, even if beamed energy can enable an $I_{s p} \approx 1000 \mathrm{~s}$ for our $\mathrm{H}_{2}+\mathrm{O}_{2}$ propellant engines, the jet power requirements for our $25 \mathrm{MT}$ payload is still more than 5 to $10 \mathrm{GW}$-an enormous amount of power.

Increasing the exhaust velocity tends to increase the reaction chamber temperature, and launch vehicle rocket engines are already operating very close to the maximum material temperatures.

Reducing the molecular weight of the exhaust will reduce the reaction chamber temperature requirements for a given $I_{s p}$ requirement. Using more hydrogen will reduce the molecular weight but the tank sizes for hydrogen are enormous even for $\operatorname{high} I_{s p}$.

Coupling received power into the exhaust is likely to be very inefficient. The excess power rejection will be a cooling challenge.

\section{LUNAR MISSION DELTA VELOCITY REQUIREMENTS}

Typical lunar mission $\Delta V$ requirements estimated using Eqs. 1 and 3 are shown in Table 3. Actual values will depend, of course, on the specific mission profile and will likely vary somewhat. It is not clear that any of these mission phases can be accommodated with beamed energy. Possibly the trans-lunar injection (TLI) could be accomplished with beamed power. A ground-based power transmitter would need to be positioned on the Earth close to the perigee point of the lunar transfer orbit, and this point might be different for each lunar mission. Perhaps a ship-based transmitter could be used for this purpose. The burn time would need to be $\approx 90 \mathrm{~s}$ to stay within view of an Earth-based power transmitter.

TABLE 3. Typical lunar mission $\Delta V$ requirements (assume leave $200-\mathrm{km}$ Earth orbit, inject into $100-\mathrm{km}$ lunar orbit).

\begin{tabular}{l|r}
\hline Trans-lunar injection & $3.133 \mathrm{~km} / \mathrm{s}$ \\
Lunar orbit injection & $1.838 \mathrm{~km} / \mathrm{s}$ \\
Lunar descent & $1.639 \mathrm{~km} / \mathrm{s}$ \\
Hover $60 \mathrm{~s}$ & $0.098 \mathrm{~km} / \mathrm{s}$ \\
Lunar ascent & $2.384 \mathrm{~km} / \mathrm{s}$ \\
Trans-Earth injection & $0.679 \mathrm{~km} / \mathrm{s}$ \\
Reentry velocity & $11.093 \mathrm{~km} / \mathrm{s}$ \\
\hline
\end{tabular}


An acceleration level of $\approx 35 \mathrm{~m} / \mathrm{s}^{2}$, or 3.5 gees, is required to add the TLI $\Delta V$ of $3.133 \mathrm{~km} / \mathrm{s}$ within the $90 \mathrm{~s}$ of visibility. The mass being accelerated will be composed of the 125 MT Ares V payload plus the 25 MT Ares I-delivered Orion crew vehicle and service module, or $\approx 150$ MT total for the TLI maneuver.

The burn time for an all-chemical engine would likely be accomplished over $\approx 10 \mathrm{~min}$ at 0.5 gees to reduce the engine size requirements. A geosynchronous satellite power transmitter could enable this TLI maneuver and perhaps some of the others near the Moon, depending on the orbit positions of the power satellite, the Moon, and the vehicle. The specific jet power for the TLI maneuver is shown in Fig. 6.

\section{BEAMED ENERGY TECHNOLOGY MATURITY}

A large number of beamed energy concepts have been presented previously [4], more than could be evaluated for maturity towards applications to human exploration missions. NASA has developed a Technology Readiness Level (TRL) definition to assist in the assessment of technology maturity. The Air Force developed a questionnaire to try to put Air Force TRL estimates on a common basis [5] and NASA has refined this questionnaire to relate to NASA missions [6]; but, of course, the results are still subjective and will reflect the biases of the individual evaluator. A TRL level of 6 is required before funding will be considered for mission applications but beamed energy propulsion (BEP) has not yet completed TRL 2. Table 4 shows the Air Force Research Laboratory (AFRL)/NASA TRL calculator questions through completion of TRL 3.

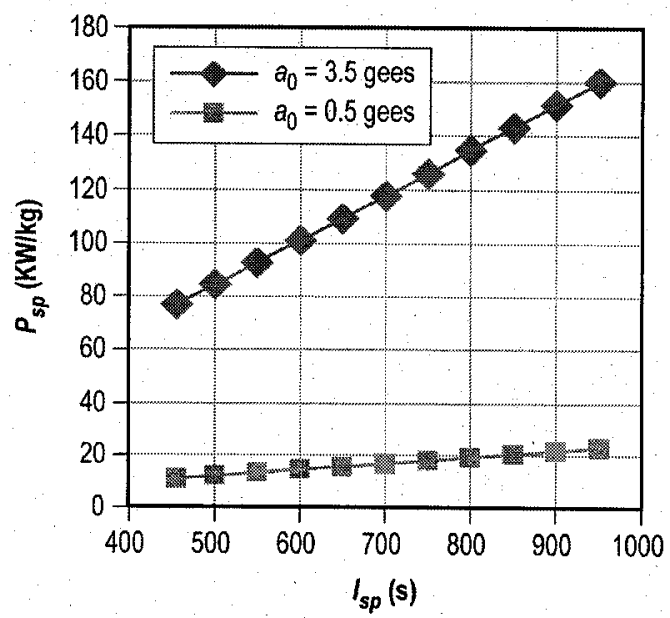

FIGURE 6. Specific jet power versus $I_{s p}$ for the TLI maneuver. 
TABLE 4. TRL questions from AFRL/NASA TRL calculator.

\begin{tabular}{|c|c|c|}
\hline$\underset{1}{\text { TRL }}$ & $\begin{array}{l}\text { Basic principles } \\
\text { observed and } \\
\text { reported }\end{array}$ & $\begin{array}{l}\text { Scientific knowledge generated underpinning hardware } \\
\text { technology concepts/applications }\end{array}$ \\
\hline & $\begin{array}{l}1 \\
2 \\
3 \\
4\end{array}$ & $\begin{array}{l}\text { Physical laws and assumptions underpinning observations verified? } \\
\text { Basic elements of technology identified? } \\
\text { Scientific knowledge generated underpinning hypothesis? } \\
\text { Peer reviewed publication of studies confirming basic principles? }\end{array}$ \\
\hline $\begin{array}{l}\text { TRL } \\
2\end{array}$ & $\begin{array}{l}\text { Technology concept } \\
\text { or application } \\
\text { formulated }\end{array}$ & $\begin{array}{l}\text { Invention begins, practical application is identified but } \\
\text { is speculative, no experimental proof or detailed analysis } \\
\text { is available to support the conjecture }\end{array}$ \\
\hline & $\begin{array}{r}1 \\
2 \\
3 \\
4 \\
5 \\
6 \\
7 \\
8 \\
9 \\
10 \\
11 \\
12\end{array}$ & $\begin{array}{l}\text { A concept formulated? } \\
\text { Basic scientific principles underpinning concept identified? } \\
\text { Preliminary analytical studies confirm basic concept? } \\
\text { Application identified? } \\
\text { Preliminary design solution identified? } \\
\text { Preliminary system studies show applications to be feasible? } \\
\text { Preliminary performance predictions made? } \\
\text { Modeling and simulation used to further refine performance } \\
\text { predictions and confirm benefits? } \\
\text { Benefits formulated? } \\
\text { Research and development approach formulated? } \\
\text { Preliminary definition of Laboratory tests and test environments } \\
\text { established? } \\
\text { Concept/application feasibility and benefits reported in scientific } \\
\text { journals/conference proceedings/technical reports? }\end{array}$ \\
\hline$\underset{3}{\text { TRL }}$ & $\begin{array}{l}\text { Analytical and/or } \\
\text { experimental } \\
\text { critical function or } \\
\text { characteristic proof- } \\
\text { of-concept }\end{array}$ & $\begin{array}{l}\text { Analytical studies place the technology in an appropriate } \\
\text { context and laboratory demonstrations, modeling and } \\
\text { simulation validate analytical prediction. }\end{array}$ \\
\hline & $\begin{array}{r}7 \\
8 \\
9 \\
10 \\
11\end{array}$ & $\begin{array}{l}\text { Critical functions/components of the concept/application identified? } \\
\text { Subsystem or component analytical predictions made? } \\
\text { Subsystem or component performance assessed by modeling } \\
\text { and simulation? } \\
\text { Preliminary key parameters performance metrics established? } \\
\text { Laboratory tests and test environments established? } \\
\text { Laboratory test support equipment and facilities completed } \\
\text { for component/proof-of-concept testing? } \\
\text { Component acquisition/fabrication completed? } \\
\text { Component tests completed? } \\
\text { Analysis of test results completed establishing key performance } \\
\text { metrics for components/subsystems? } \\
\text { Analytical verification of critical functions from proof-of-concept } \\
\text { made? } \\
\text { Analytical and experimental proof-of-concept documented? }\end{array}$ \\
\hline
\end{tabular}

The components evaluated for Technology Readiness and some of the concerns are shown in Table 5. 
TABLE 5. BEP components assessed for technology readiness.

\begin{tabular}{c|l}
\hline BEP Components & \multicolumn{1}{c}{ Considerations } \\
\hline $\begin{array}{c}\text { Laser BEP } \\
\text { Receiver }\end{array}$ & \\
Ablation \\
Photo cells & $\begin{array}{l}\text { Optics, cooling } \\
\text { Conversion efficiency, cooling, drag, } \\
\text { high power, size, and weight }\end{array}$ \\
Thrust augmentation & \multicolumn{1}{c}{ Cooling, effects on optics, $I_{s p}$} \\
Ablation, LSD & Cooling, magnet weight \\
MHD & high power, coherence \\
Transmitter & Size, drag, high power, cooling \\
$\mu$-Wave & Cooling, magnet weight \\
Receiver, rectenna \\
Thrust, aug., MHD \\
Transmitter & \\
Power source & \\
Ground based & Energy storage, high power, and energy \\
Space based & Availability, maintainability \\
\hline
\end{tabular}

The results on my assessment of the TRL levels are shown in Table 6. So, from my perspective, beamed energy propulsion is close to completing TRL 2 and has some activity started on TRL 3.

TABLE 6. A 2007 TRL evaluation of beamed energy propulsion components for human exploration missions.

\begin{tabular}{|c|c|c|c|c|c|c|c|c|c|}
\hline \multirow[b]{2}{*}{ TRL } & \multirow[b]{2}{*}{ Q's } & \multicolumn{3}{|c|}{ Laser } & \multicolumn{3}{|c|}{$\mu$-Wave } & \multicolumn{2}{|c|}{ Power Source } \\
\hline & & Receiver & $\begin{array}{c}\text { Thrust } \\
\text { Aug. }\end{array}$ & Transmit & Receiver & $\begin{array}{c}\text { Thrust } \\
\text { Aug. }\end{array}$ & Transmit & Ground & Space \\
\hline \multirow[t]{4}{*}{1} & 1 & $\checkmark$ & $\checkmark$ & $\checkmark$ & $\checkmark$ & $\checkmark$ & $\checkmark$ & $\checkmark$ & $\checkmark$ \\
\hline & 2 & $\checkmark$ & $\checkmark$ & $\checkmark$ & $\checkmark$ & $\checkmark$ & $\checkmark$ & $\checkmark$ & $\checkmark$ \\
\hline & 3 & $\checkmark$ & $\checkmark$ & $\checkmark$ & $\checkmark$ & $\checkmark$ & $\checkmark$ & $\checkmark$ & $\checkmark$ \\
\hline & 4 & $\checkmark$ & $\checkmark$ & $\checkmark$ & $\checkmark$ & $\checkmark$ & $\checkmark$ & $\checkmark$ & $\checkmark$ \\
\hline \multirow[t]{12}{*}{2} & 1 & $\checkmark$ & $\checkmark$ & $\checkmark$ & $\checkmark$ & $\checkmark$ & $\checkmark$ & $\checkmark$ & $\checkmark$ \\
\hline & 2 & $\checkmark$ & $\checkmark$ & $\checkmark$ & $\checkmark$ & $\checkmark$ & $\checkmark$ & $\checkmark$ & $\checkmark$ \\
\hline & 3 & $\checkmark$ & $\checkmark$ & $\checkmark$ & $\checkmark$ & $\checkmark$ & $\checkmark$ & $\checkmark$ & $\checkmark$ \\
\hline & 4 & $\checkmark$ & $\checkmark$ & $\checkmark$ & $\checkmark$ & $\checkmark$ & $\checkmark$ & $\checkmark$ & $\checkmark$ \\
\hline & 5 & $\checkmark$ & $\checkmark$ & $\checkmark$ & $\checkmark$ & $\checkmark$ & $\checkmark$ & $\checkmark$ & $\checkmark$ \\
\hline & 6 & $\checkmark$ & $\checkmark$ & $\checkmark$ & $\checkmark$ & $\checkmark$ & $\checkmark$ & $\checkmark$ & $\checkmark$ \\
\hline & 7 & $50 \%$ & $50 \%$ & $50 \%$ & $75 \%$ & $75 \%$ & $75 \%$ & $\checkmark$ & $\checkmark$ \\
\hline & 8 & $\checkmark$ & $\checkmark$ & $\checkmark$ & $\checkmark$ & $\checkmark$ & $\checkmark$ & $\checkmark$ & $\checkmark$ \\
\hline & 9 & $50 \%$ & $50 \%$ & $50 \%$ & $50 \%$ & $50 \%$ & $50 \%$ & $50 \%$ & $50 \%$ \\
\hline & 10 & $50 \%$ & $50 \%$ & $50 \%$ & $50 \%$ & $50 \%$ & $50 \%$ & $50 \%$ & $50 \%$ \\
\hline & 11 & $\checkmark$ & $\checkmark$ & $\checkmark$ & $\checkmark$ & $\checkmark$ & $\checkmark$ & $\checkmark$ & $\checkmark$ \\
\hline & 12 & $\checkmark$ & $\checkmark$ & $\checkmark$ & $\checkmark$ & $\checkmark$ & $\checkmark$ & $\checkmark$ & $\checkmark$ \\
\hline \multirow[t]{9}{*}{3} & 1 & $\checkmark$ & $\checkmark$ & $\checkmark$ & $\checkmark$ & $\checkmark$ & $\checkmark$ & $\checkmark$ & $\checkmark$ \\
\hline & 2 & $50 \%$ & $50 \%$ & $50 \%$ & $50 \%$ & $50 \%$ & $50 \%$ & $50 \%$ & $50 \%$ \\
\hline & 3 & $50 \%$ & $50 \%$ & $50 \%$ & $50 \%$ & $50 \%$ & $50 \%$ & $50 \%$ & $50 \%$ \\
\hline & 4 & $50 \%$ & $50 \%$ & $50 \%$ & $50 \%$ & $50 \%$ & $50 \%$ & $50 \%$ & $50 \%$ \\
\hline & 5 & $50 \%$ & $50 \%$ & $50 \%$ & $50 \%$ & $50 \%$ & $50 \%$ & $50 \%$ & $50 \%$ \\
\hline & 6 & - & - & - & - & - & - & - & - \\
\hline & 7 & - & - & $\therefore$ & - & - & - & - & - \\
\hline & 8 & - & - & - & - & - & - & - & - \\
\hline & 9 & - & - & - & $\begin{array}{lll}- \\
-\end{array}$ & - & - & - & - \\
\hline
\end{tabular}




\section{CONCLUSIONS}

Recognizing that this top-level analysis of vehicle performance requirements does not address the physics of implementation of the components, it does imply that beamed energy propulsion has the potential of significantly improving the payload mass fraction, a beneficial feature for human exploration. To achieve a payload mass fraction of $7.5 \%$ will require a high $I_{s p}$ capability, probably $>800 \mathrm{~s}$, without a large vehicle mass increase and, to be competitive, this must also be accomplished without much increase in launch costs. Applications to the human lunar missions, other than launch to LEO, are probably not practical unless significant space-based infrastructure is developed first. A quick assessment of the Technology Readiness Level to support human exploration missions indicates that the necessary BEP components are close to completing TRL 2.

\section{REFERENCES}

1. W. C. Nelson and E. E. Loft, Space Mechanics, Prentice-Hall, 1962, p. 95.

2. P. G. Hill and C. R. Peterson, Mechanics and Thermodynamics of Propulsion, 2nd Ed., AddisonWesley, Reading, MA, 1992, pp. 469-512.

3. S. J. Isakowitz, International Reference Guide to Space Launch Systems, AIAA, 1991, p. 245.

4. A. V. Pakhomov and L. N. Myrabo, Beamed Energy Propulsion, Third International Symposium on Beamed Energy Propulsion, American Institute of Physics, 2005.

5. W. Nolte, "AFRL TRL Calculator," https://acc.dau.mil/CommunityBrowser.aspx?id=25811, accessed August 27, 2007.

6. J. Bilbro, "AFRL/NASA TRL Calculator," (web site not yet available). 


\title{
An Exploration Perspective of Beamed Energy Propulsion
}

\author{
For
}

The Fifth International Symposium on

Beamed Energy Propulsion

Keahou Beach, Hawaii

November 12-15, 2007 


\section{An Exploration Perspective on Beamed Energy Propulsion}

\section{Contents}

- Vision for Space Exploration

- NASA's Current Plans for Human Exploration

- Launch Vehicle Requirements to Support Human Exploration

- The Beamed Energy Challenge

- Basis of Comparison

- Payload Fraction and GLOW

- Total Lift-Off Jet Power

- Psuedo-Concept for a Beamed Power Launch Vehicle

- Jet Power

- Payload Mass Fraction

- Areas of Concern

- Lunar Mission

- Trans Lunar Injection

- Technology Readiness

- BEP Components

- Technology Evaluation

- Conclusions

- References 


\section{Vision for Space Exploration}

- Safely fly the Space Shuttle until 2010

- Complete the International Space Station

- Develop a balanced program of science, exploration, and aeronautics

- Develop and fly the Orion Crew Exploration Vehicle (CEV)

- Return to the Moon no later than 2020

- Promote international and commercial participation in exploration

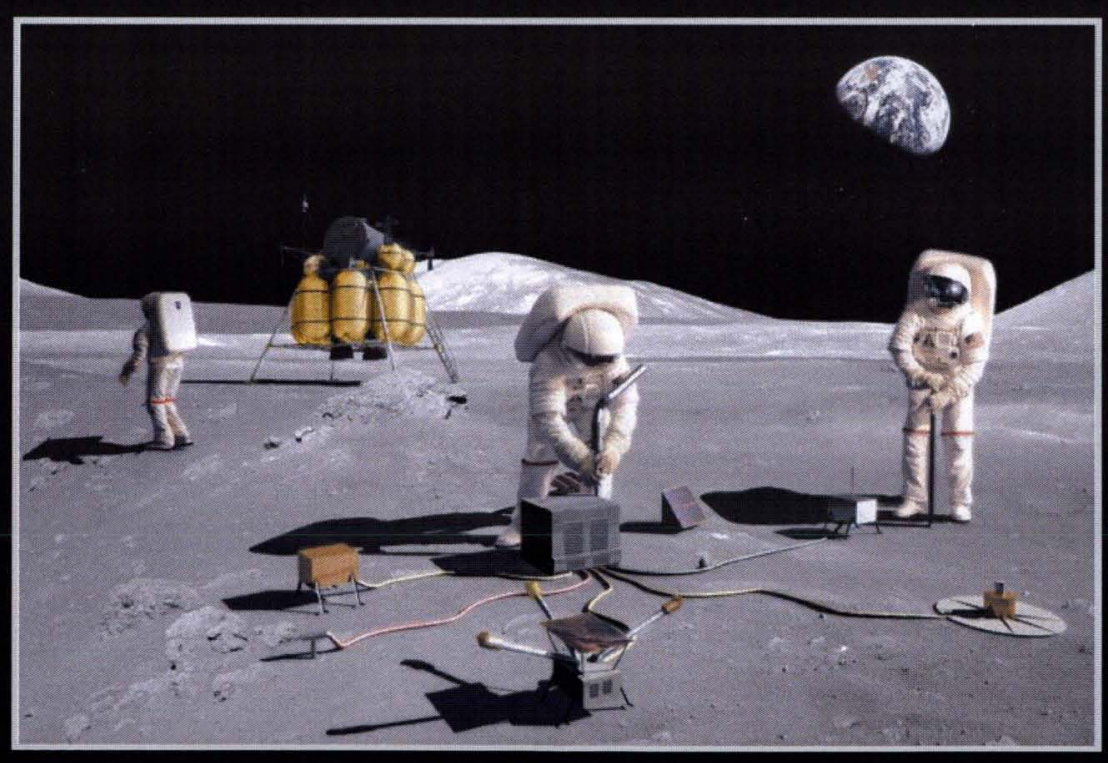

"The next steps in returning to the Moon and moving onward to Mars, the near-Earth asteroids, and beyond, are crucial in deciding the course of future space exploration. We must understand that these steps are incremental, cumulative, and incredibly powerful in their ultimate effect."

- NASA Administrator Michael Griffin October 24, 2006 


\section{NASA's Current Plans for}

Human Exploration

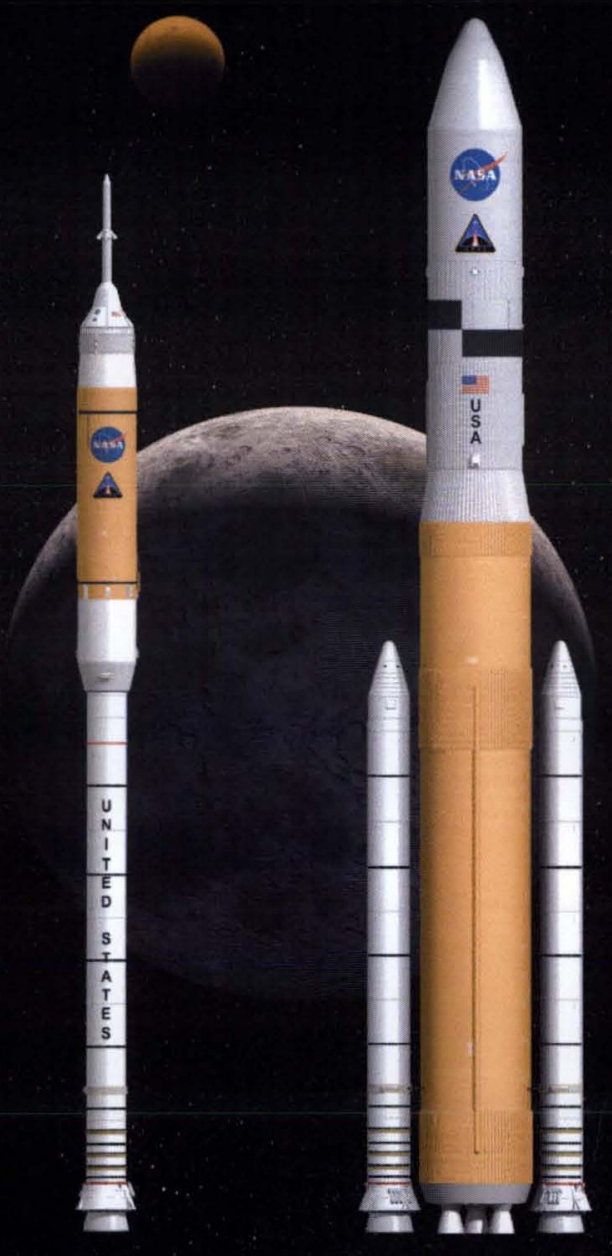




\section{Launch Vehicle Requirements to Support Human Exploration}

- Human exploration of space requires enormous quantities of material to be delivered to space on a somewhat regular basis.

- Will likely require more than 100 metric tons to Low Earth Orbit (LEO) for each launch,

- For support of a lunar base with logistics flights every six months or so, including:

- Trans-lunar transfer vehicles.

- Lander vehicles transporting lunar base equipment and consumables to the lunar surface.

- Ascent and recovery vehicles to return crews to the earth.

- The current NASA plan is to utilize a heavy lift vehicle, Ares V, to deliver about 120 MT to LEO and,

- A smaller 22 MT payload launch vehicle, Ares I,

- To deliver human crews in the crew exploration vehicle, Orion, to the space station.

- Or to rendezvous with the Ares $\mathrm{V}$ payloads destined for the moon. 


\section{The Beamed Energy Challenge}

Beamed energy propulsion can become competitive with current launch vehicle technologies when it can provide compelling benefits to performance and costs.

- For example, doubling the payload fraction of a launch vehicle without increasing launch costs would be a compelling benefit.

- $\mathrm{m}_{\mathrm{pl}} / \mathrm{m}_{0}$, where $\mathrm{m}_{\mathrm{pl}}$ is the mass of the payload and $\mathrm{m}_{0}$ is the Gross Lift-Off Weight or GLOW

- To support exploration missions the vehicle should deliver at least 25 MT to LEO.

- Larger vehicles delivering 125 MT to LEO would be desirable but their power requirements would also grow by a factor of 5 .

The focuses here will be on the following:

- Some of the implications of increasing the payload fraction of a launch vehicle, 25 MT to LEO.

- A quick look at trans-lunar injection.

- Concludes with an assessment of the Technology Readiness Level (TRL) for some Beamed Energy Propulsion components, from a Human Exploration perspective. 


\section{Basis of Comparison}

Find the lift-off jet power required for an SSTO vehicle to deliver 25 MT to LEO for various $I_{s p}$.

- Assume a lift-off acceleration $\mathrm{a}_{0}$ of 1.4 gees $(13.7 \mathrm{~m} / \mathrm{s})$.

- Use Rocket Equation to find vehicle propellant mass fraction, $\mathrm{f}_{\mathrm{f}}$

$$
f_{f}=1-\exp \left(-\Delta V / v_{e x}\right)
$$

where $\quad v_{\text {ex }}=g_{0}{ }^{*} I_{s p}$

and $\quad \Delta \mathrm{V}=9.26 \mathrm{KM} / \mathrm{s} \quad$ from Table 1.

- $A n$ Isp $=456 \mathrm{~s}(\mathrm{H} 2+\mathrm{O} 2$ engines like the Shuttle $)$ then gives $\mathrm{f}_{\mathrm{f}}=87.4 \%$.

- As will be seen, this does not lead to a practical solution without some augmentation.

\begin{tabular}{|l|l|l|l}
\hline $\mathrm{v}_{\mathrm{p}}$ & 7.97 & $\mathrm{~km} / \mathrm{s}$ & Perigee velocity at surface of airless Earth \\
\hline $\mathrm{v}_{\mathrm{e}}$ & -0.4 & $\mathrm{~km} / \mathrm{s}$ & Velocity gained from rotation of Earth at $28^{\circ}$ Latitude \\
\hline $\mathrm{v}_{\mathrm{GL}}$ & 1.1 & $\mathrm{~km} / \mathrm{s}$ & Gravity losses \\
\hline $\mathrm{v}_{\text {drag }}$ & 0.5 & $\mathrm{~km} / \mathrm{s}$ & Drag losses \\
\hline $\mathrm{v}_{\text {steer }}$ & 0.1 & $\mathrm{~km} / \mathrm{s}$ & Steering losses \\
\hline $\mathrm{v}_{\text {circ }}$ & 0.06 & $\mathrm{~km} / \mathrm{s}$ & Velocity required to circularize orbit at apogee \\
\hline$\Delta \mathrm{V}$ & 9.26 & $\mathrm{~km} / \mathrm{s}$ & Ideal Delta Velocity
\end{tabular}

Table 1. Typical Ideal Velocity Components for Launch to a $200 \mathrm{~km}$ altitude orbit 


\section{Payload Fraction and GLOW}

- The payload fraction $B$ can be found from

$$
B=m_{p l} / m_{0}=\left(f_{s}-f_{f}\right) / f_{s}
$$

- Where the stage fraction $\mathrm{f}_{\mathrm{s}}$ is the ratio of the propellant mass to the total stage mass without the payload. It is determined from design and manufacturing capability.

- From Table 2 select $\mathrm{f}_{\mathrm{s}}=89 \%$ for this analysis, giving $B=1.8 \%$.

- $\mathrm{M}_{0}$ is the Gross Lift-Off Weight (GLOW).

A payload mass $m_{p l}=25$ MT implies that $m_{0}=1380$ MT.

\section{Stage Propellant Mass Fraction for Historical Stages and EELV (from Isakowitz)}

\begin{tabular}{|c|c|c|c|c|c|c|}
\hline Vehicle & Stage & Propellant & Fuel Mass Kkg & Gross Mass Kkg & Thrust KN & $\begin{array}{l}\text { Stage Propellant } \\
\text { Mass Fraction, fs }\end{array}$ \\
\hline Saturn V & $\begin{array}{l}\text { S-IC } \\
\text { S-II } \\
\text { S-IVB }\end{array}$ & $\begin{array}{l}\text { LOX/RP-1 } \\
\text { LOX/H2 } \\
\text { LOX/H2 }\end{array}$ & $\begin{array}{r}2080 \\
450 \\
108\end{array}$ & $\begin{array}{r}2210 \\
486 \\
119\end{array}$ & $\begin{array}{r}34500 \\
5115 \\
690\end{array}$ & $\begin{array}{l}0.9412 \\
0.9259 \\
0.9076\end{array}$ \\
\hline Titan IV & $\begin{array}{l}\text { Stg } 1 \\
\text { Stg } 2 \\
\text { Centaur }\end{array}$ & $\begin{array}{l}\text { N2O4/AZ50 } \\
\text { N2O4/AZ51 } \\
\text { LOX/H2 }\end{array}$ & $\begin{array}{r}155 \\
35.1 \\
20.32\end{array}$ & $\begin{array}{r}163 \\
39.6 \\
23.86\end{array}$ & $\begin{array}{r}2410 \\
462 \\
146\end{array}$ & $\begin{array}{l}0.9509 \\
0.8864 \\
0.8516\end{array}$ \\
\hline Delta IV-H & $\begin{array}{l}\text { Stg } 1 \\
\operatorname{Stg} 2\end{array}$ & $\begin{array}{l}\text { LOX/H2 } \\
\text { LOX/H2 }\end{array}$ & $\begin{array}{r}199.6 \\
27.2\end{array}$ & $\begin{array}{l}226.4 \\
30.71\end{array}$ & $\begin{array}{r}2890 \\
110\end{array}$ & $\begin{array}{l}0.8816 \\
0.8857\end{array}$ \\
\hline Atlas $\mathrm{V}$ & $\begin{array}{l}\text { stg } 1 \\
\text { Centaur III }\end{array}$ & $\begin{array}{l}\text { LOX/RP-1 } \\
\text { LOX/H2 }\end{array}$ & $\begin{array}{l}284.5 \\
20.83\end{array}$ & $\begin{array}{l}305.4 \\
22.96\end{array}$ & $\begin{array}{l}860.2 \\
198.4\end{array}$ & $\begin{array}{l}0.9316 \\
0.9072\end{array}$ \\
\hline
\end{tabular}




\section{Total Lift-Off Jet Power}

\section{Point of Comparison}

- Specific jet power

$$
P_{s p}=a_{0}^{*} v_{e x} / 2 \sim 31 \mathrm{KW} / \mathrm{kg}
$$

for $\mathrm{v}_{\mathrm{ex}}=456 \mathrm{~s}$, and $\mathrm{a}_{0}=1.4$ gees.

- Jet Power for Lift-Off

$$
\mathrm{P}_{\mathrm{v}}=\mathrm{m}_{0}{ }^{*} \mathrm{P}_{\mathrm{sp}} \sim 42 \mathrm{GW} \text {. }
$$

- Not practical, margins too slim.

Higher $I_{s p}$ (with No decrease in $f_{s}$ )

- Substantially reduced Jet Power.

- Substantially increased payload Fraction.

\section{Beamed Energy}

- An avenue?

- Possibly the only avenue!
Total Lift-Off Jet Power and Payload Ratio for a 25 MT Payload H2+O2 SSTO Vehicle

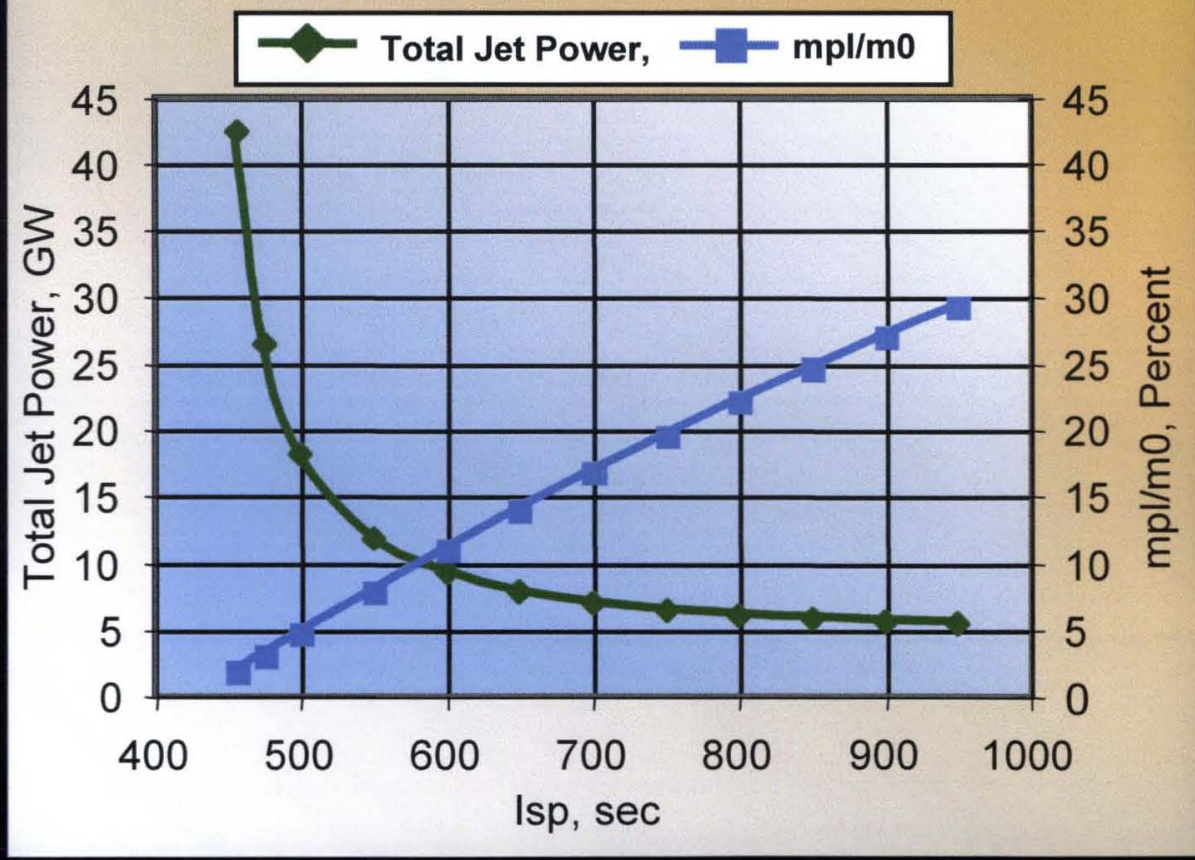




\section{Pseudo-Concept for a Beamed Power Launch Vehicle}

\section{Pseudo-Concept}

- Without defining exactly how the Beamed Energy is transmitted, received, or converted to increase the Jet Power.

- Assume that the previous SSTO vehicle, with engines using $\mathrm{H}_{2}+\mathrm{O}_{2}$, have the Isp augmented.

- Assume the Beamed Energy Equipment on board the vehicle adds mass $m_{\mathrm{BE}}$ and is treated as additional payload.

\section{GLOW, $m_{0}$}

- For $m_{\mathrm{BE}}=0$, An Isp $=550 \mathrm{~s}$ is in the knee.

- For $m_{B E}=m_{p l}$, An lsp $=700 \mathrm{~s}$ is needed for equivalent performance.

- For $m_{\mathrm{BE}}=2 \mathrm{~m}_{\mathrm{pl}}$, An Isp $=850 \mathrm{~s}$ is needed for equivalent performance.

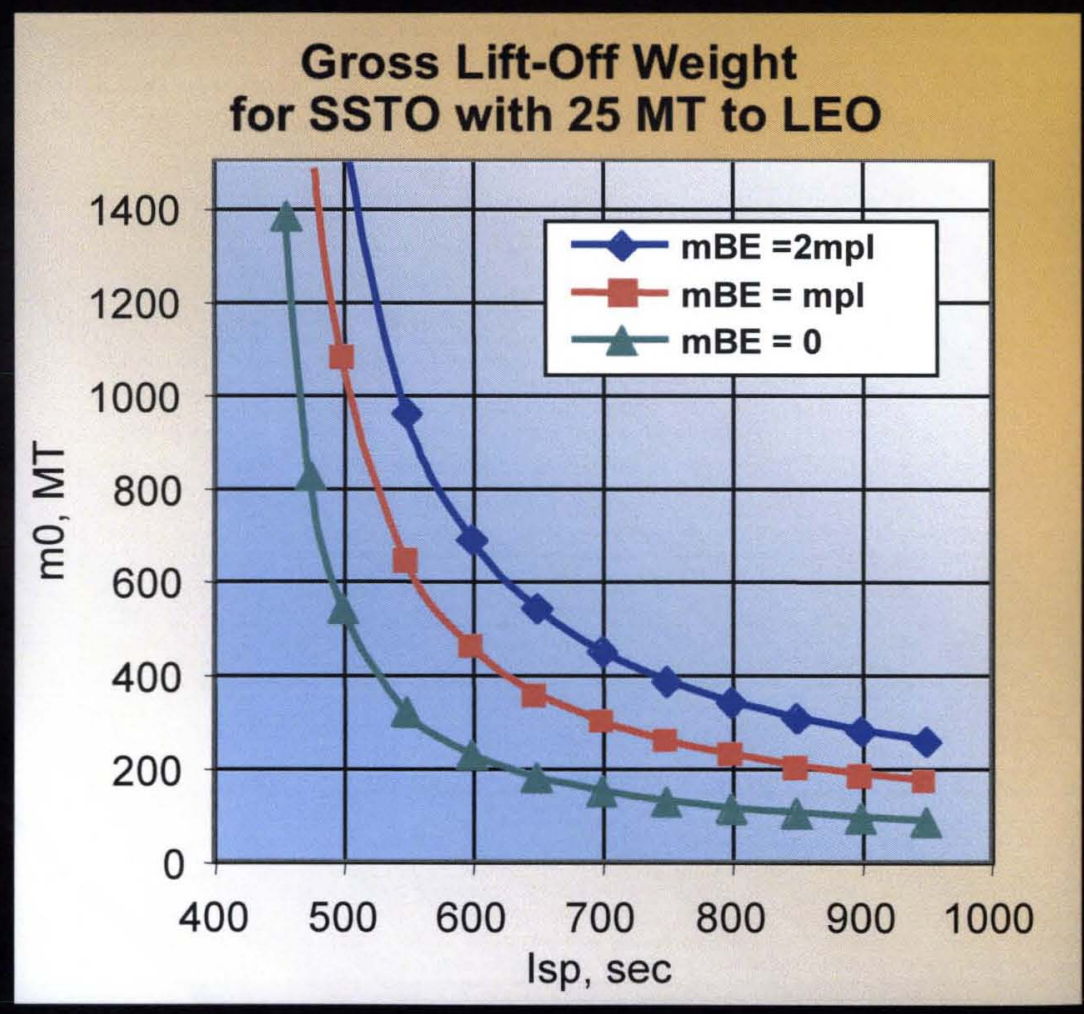




\section{Jet Power}

- Assume Lift-Off acceleration $a_{0}=1.4$ gees.

- Specific Power for all acceleration levels increases with $I_{s p}$, indicating more energy is in the propellant.

- $\mathrm{m}_{\mathrm{BE}}>0$ increases the Lift-Off Jet Power.
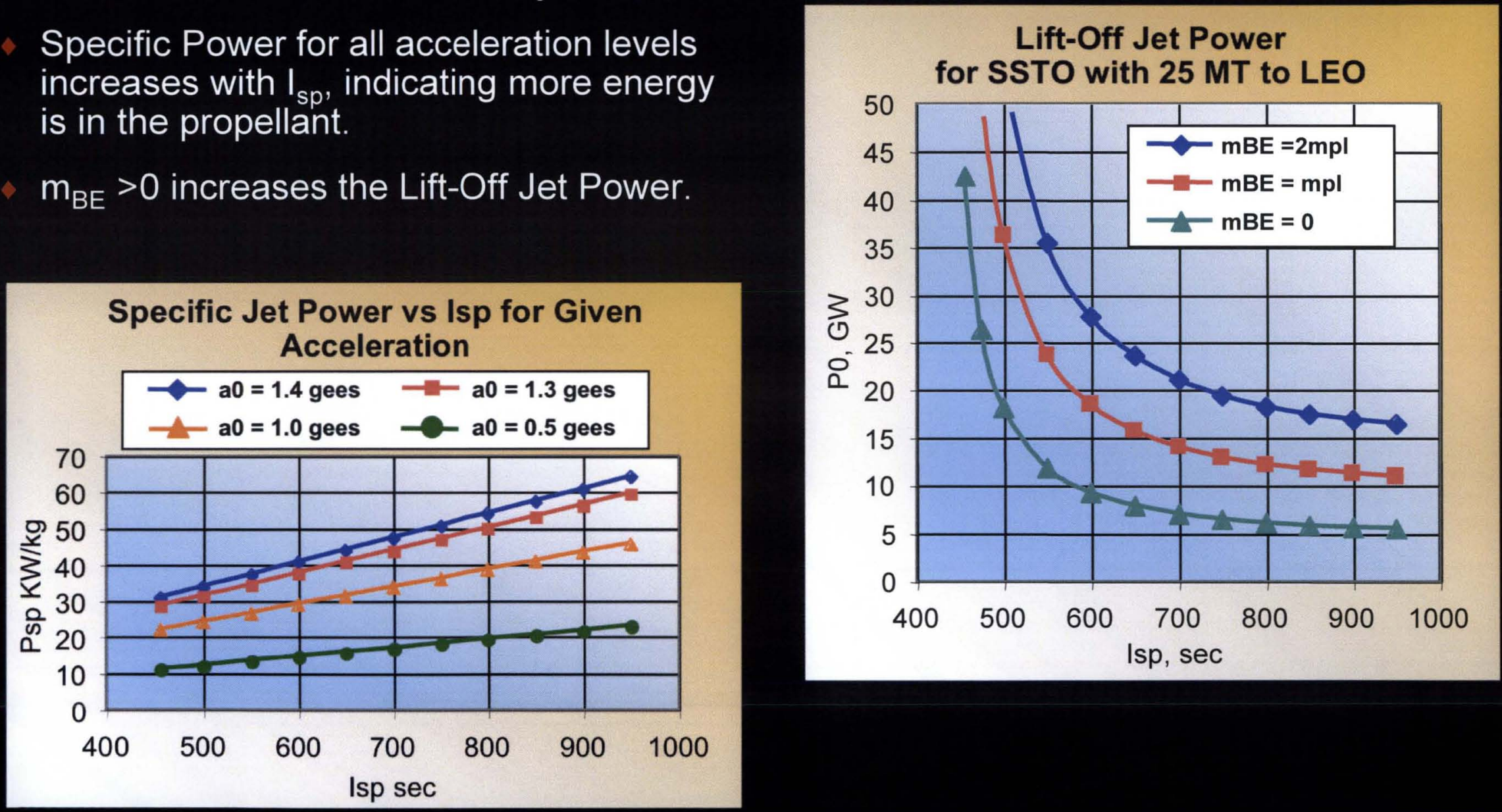


\section{Payload Mass Fraction}

- Increasing $\mathrm{m}_{\mathrm{BE}}>0$ compromises Payload Mass Fraction.

- However, an $\mathrm{I}_{\mathrm{sp}}=850 \mathrm{~s}$ still has $7.5 \%$ even with $\mathrm{m}_{\mathrm{BE}}=2 \mathrm{~m}_{\mathrm{pl}}$.

$I_{s p}$ needs to be very high, but $m_{B E}$ needs to be less than $m_{p l}$.

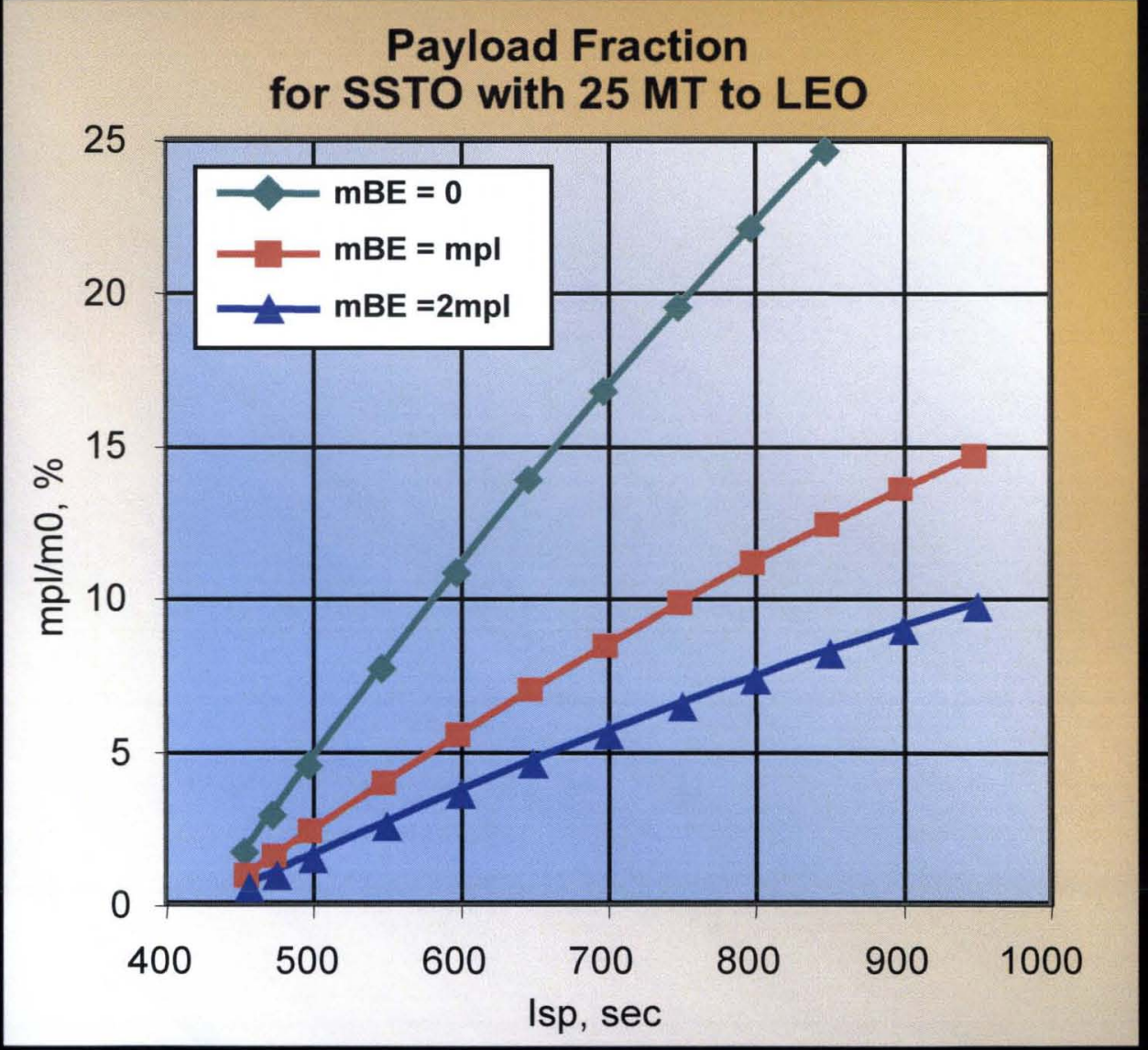




\section{Areas of Concern}

New potential solutions also bring new concerns and there are many that need to be mentioned.

- One obvious concern is that, even if beamed energy can enable an $\mathrm{I}_{\mathrm{sp}} \sim 1000$ seconds for our $\mathrm{H} 2+\mathrm{O} 2$ propellant engines, the jet power requirements for our $25 \mathrm{MT}$ payload is still more than 5 to $10 \mathrm{GW}$, an enormous amount of power.

- Increasing the exhaust velocity tends to increase the reaction chamber temperature, and launch vehicle rocket engines are already operating very close to the maximum material temperatures.

- Reducing the molecular weight of the exhaust will reduce the reaction chamber temperature requirements for a given Isp requirement. Using more hydrogen will reduce the molecular weight but the tank sizes for hydrogen are enormous even for high $I_{s p}$

- Coupling received power into the exhaust is likely to be very inefficient. The excess power rejection will be a cooling challenge. 


\section{Lunar Mission}

- Lunar Mission $\Delta \mathrm{V}$ s estimated using the energy integral below.

- It is not clear that any of these mission phases can be accommodated with beamed energy.

- Possibly the TLI could be accomplished with Beamed Power.

- A ground-based power transmitter would need to be positioned on the earth close to the perigee point of the lunar transfer orbit, and this point might be different for each lunar mission.

- Perhaps a ship-based transmitter could be used for this purpose.

$v^{2}=\mu\left(\frac{2}{(r 0+h)}-\frac{1}{a}\right) \quad \begin{array}{lll}\text { Typical Lunar Mission } \Delta V & \text { Requirements } \\ \text { assume leave } 200 \mathrm{~km} \text { Earth orbit, inject into } 100 \mathrm{~km} \text { Lunar orbit } \\ \text { Trans Lunar Injection } & 3.133 \mathrm{~km} / \mathrm{s} \\ \text { Lunar Orbit Injection } & 1.838 \mathrm{~km} / \mathbf{s} \\ \text { Lunar Descent } & 1.639 \mathrm{~km} / \mathrm{s} \\ \text { Hover } 60 \mathrm{~s} & 0.098 \mathrm{~km} / \mathrm{s} \\ \text { Lunar Ascent } & 2.384 \mathrm{~km} / \mathrm{s} \\ \text { Trans-Earth Injection } & 0.679 \mathrm{~km} / \mathrm{s} \\ \text { Re-entry Velocity } & 11.093 \mathrm{~km} / \mathrm{s}\end{array}$




\section{Trans Lunar Injection}

\section{Ground or Ship Based Transmitter}

- The TLI burn time would need to be less than 90 seconds to stay within view of an Earth based power transmitter.

- This implies an average acceleration level of about 3.5 gees.

- This high acceleration level implies very high specific power levels $>80$ $\mathrm{KW} / \mathrm{kg}$.

\section{Space Based Transmitter}

- The TLI burn time can be extended to $600 \mathrm{~s}$.

- This reduces the acceleration level to about $\mathrm{a} 0=0.5$ gees and Psp $\sim 10$ to $20 \mathrm{KW} / \mathrm{kg}$.

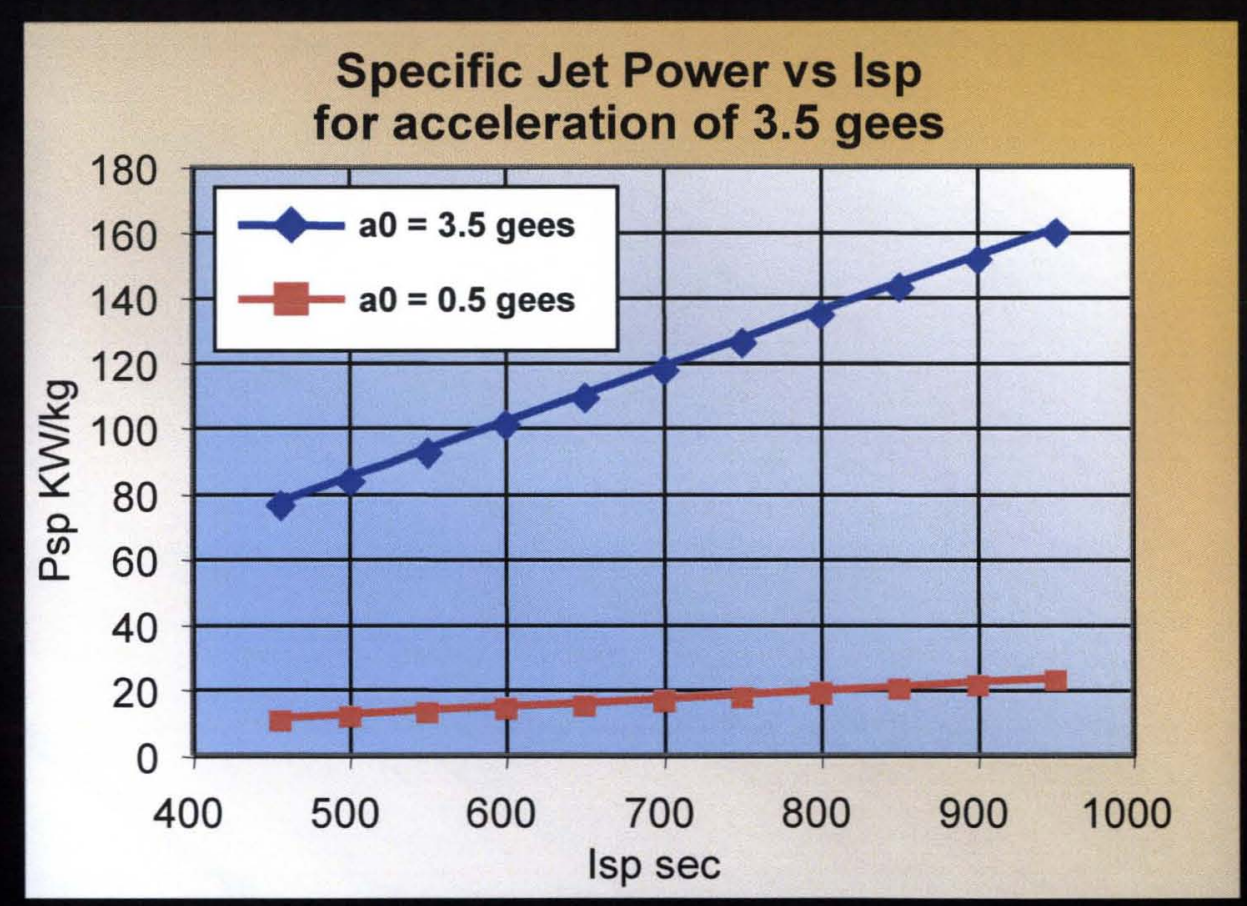




\section{Technology Readiness}

\section{TRL Questions from AFRL/NASA TRL Calculator}

\section{TRL Statement}

1 Basic principles observed and reported

1
2
3
4

2 Technology concept or application formulated

1

2

3

4

5

6

7

8

9

10

11

12

\section{Definition and Questions}

Scientific knowledge generated underpinning hardware technology concepts/applications.

Physical laws and assumptions underpinning observations verified?

Basic elements of technology identified?

Scientific knowledge generated underpinning hypothesis?

Peer reviewed publication of studies confirming basic principles?

Invention begins, practical application is identified but is speculative, no experimental proof or detailed analysis is available to support the conjecture.

A concept formulated?

Basic scientific principles underpinning concept identified?

Preliminary analytical studies confirm basic concept?

Application identified?

Preliminary design solution identified?

Preliminary system studies show application to be feasible?

Preliminary performance predictions made?

Modeling \& Simulation used to further refine performance predictions and confirm benefits?

Benefits formulated?

Research \& development approach formulated?

Preliminary definition of Laboratory tests and test environments established?

Concept/application feasibility \& benefits reported in scientific journals/conference proceedings/technical reports? 


\section{Technology Readiness (continued)}

\begin{tabular}{|c|c|}
\hline$T R L$ & Statement \\
\hline 3 & $\begin{array}{l}\text { Analytical and/ or } \\
\text { experimental critical } \\
\text { function or characteristic } \\
\text { proof-of-concept }\end{array}$ \\
\hline & 1 \\
\hline & 2 \\
\hline & 3 \\
\hline & 4 \\
\hline & 5 \\
\hline & 6 \\
\hline & 7 \\
\hline & 8 \\
\hline & 9 \\
\hline & 10 \\
\hline & 11 \\
\hline
\end{tabular}

\section{Definition and Questions}

Analytical studies place the technology in an appropriate context and laboratory demonstrations, modeling and simulation validate analytical prediction.

Critical functions/components of the concept/application identified?

Subsystem or component analytical predictions made?

Subsystem or component performance assessed by Modeling and Simulation?

Preliminary key parameters performance metrics established?

Laboratory tests and test environments established?

Laboratory test support equipment and facilities completed for component/proof-of-concept testing?

Component acquisition/fabrication completed?

Component tests completed?

Analysis of test results completed establishing key performance metrics for components/subsystems?

Analytical verification of critical functions from proof-of-concept made?

Analytical and experimental proof-of-concept documented? 


\title{
BEP Components
}

\section{BEP Components Assessed for Technology Readiness}

\author{
BEP Components \\ Laser BEP \\ Receiver \\ Ablation \\ Photo Cells \\ Thrust Augmentation \\ Ablation, LSD \\ MHD \\ Transmitter

\section{$\mu$-Wave} \\ Receiver - rectenna \\ Thrust Aug. - MHD \\ Transmitter \\ Power Source \\ Ground based \\ Space Based
}

\section{Considerations}

Optics, Cooling

Conversion Efficiency, Cooling, Drag, High power, Size and Weight

Cooling, Effects on Optics, Isp

Cooling, Magnet Weight

High Power, Coherence

Size, Drag, High Power, Cooling

Cooling, Magnet Weight

High Power

Energy Storage, High Power and Energy

Availability, Maintainability 


\section{Technology Evaluation}

\section{A 2007 TRL Evaluation of Beamed Energy Propulsion Components for}

Human Exploration Mission

TRL Q'S

1
$\mu$-Wave

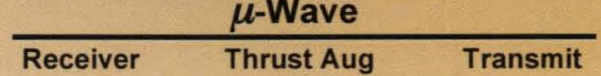

$\begin{array}{lll}\text { Receiver Thrust Aug } & \text { Transmit }\end{array}$

1

2

(n)

2

5

6

7

8
9

10

11

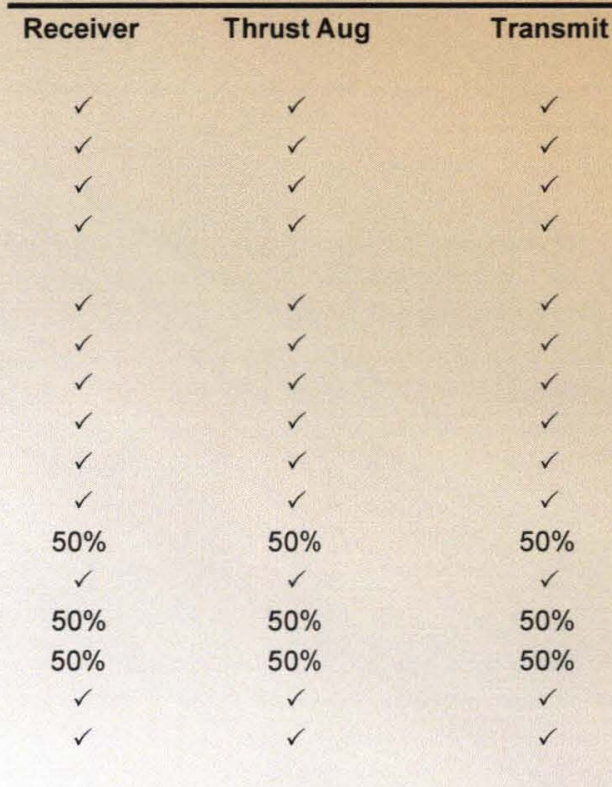

$50 \%$

$50 \%$

$50 \%$

$50 \%$

$\begin{array}{ccc}\checkmark & \checkmark & \checkmark \\ \checkmark & \checkmark & \checkmark \\ \checkmark & \checkmark & \checkmark \\ \checkmark & \checkmark & \\ & & \checkmark \\ \checkmark & \checkmark & \checkmark \\ \checkmark & \checkmark & \checkmark \\ \checkmark & \checkmark & \checkmark \\ \checkmark & \checkmark & \checkmark \\ \checkmark & \checkmark & \checkmark \\ \checkmark & \checkmark & \checkmark \\ 75 \% & 75 \% & 50 \% \\ \checkmark & \checkmark & 50 \% \\ 50 \% & 50 \% & \checkmark \\ 50 \% & 50 \% & \checkmark \\ \checkmark & \checkmark & \\ \checkmark & \checkmark & \checkmark \\ & & 50 \% \\ \checkmark & \checkmark & 50 \% \\ 50 \% & 50 \% & - \\ 50 \% & 50 \% & 50 \% \\ 50 \% & 50 \% & \\ 50 \% & - & \\ - & & \end{array}$

Power Source

Ground Space

$\begin{array}{cc}50 \% & 50 \% \\ 50 \% & 50 \% \\ 50 \% & 50 \% \\ 50 \% & 50 \% \\ - & - \\ - & - \\ - & - \\ - & - \\ - & - \\ - & -\end{array}$


Conclusions

- This top level analysis of vehicle performance requirements

- Does not address the physics of implementation of the components, but,

- It does imply that Beamed Energy Propulsion has the potential of significantly improving the payload mass fraction, a beneficial feature for human exploration.

- To achieve a payload mass fraction of $7.5 \%$

- Will require a high Isp capability, probably greater than $800 \mathrm{~s}$,

- Without a large vehicle mass increase and,

- To be competitive, this must also be accomplished without much increase in launch costs.

- Applications to the human lunar missions, other than launch to LEO, are probably not practical unless significant space based infrastructure is developed first.

- A quick assessment of the Technology Readiness Level to support Human Exploration missions indicates that the necessary BEP components have almost completed TRL 2. 


\section{References}

Nelson and Loft, Space Mechanics, Prentice-Hall, 1962, p. 95

Hill, P.G., and Peterson, C.R., Mechanics and Thermodynamics of Propulsion, 2nd Ed., Addison-Wesley, Reading, MA, 1992, pp. 469-512.

Isakowitz, S.J., International Reference Guide to Space Launch Systems, AIAA, 1991 , p. 245.

Nolte, William, "AFRL TRL Calculator", accessed 8-272007https://acc.dau. mil/CommunityBrowser.aspx?id=25811

Pokhomov, Andrew, Beamed Energy Propulsion, Third International Symposium on Beamed Energy Propulsion, American Institute of Physics, 2005

Bilbro, James, "AFRL/NASA TRL Calculator", (web site not yet available) 


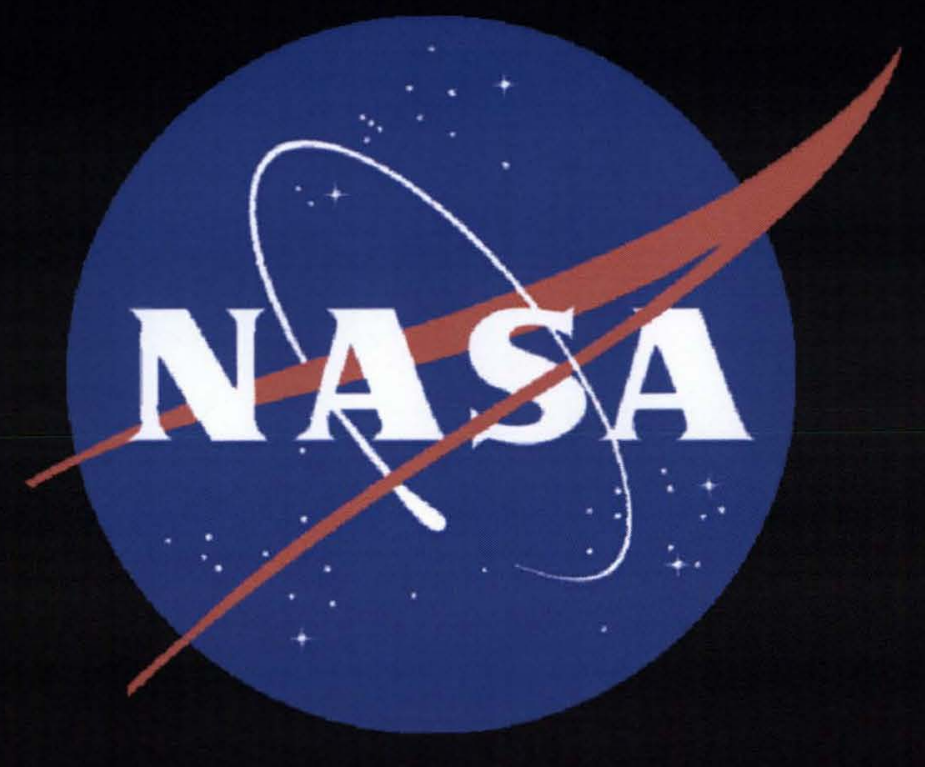

